\title{
SER MENINO NEGRO: UMA ANÁLISE EM LIVROS DE LITERATURA INFANTIL
}

\author{
Tarcia Regina da Silva (UPE)* \\ https://orcid.org/0000-0002-4392-3468 \\ Ernani Martins dos Santos (UPE)** \\ https://orcid.org/0000-0002-3824-986X
}

\section{RESUMO}

Este artigo tem como foco a análise de livros de literatura infantil que têm como protagonistas meninos negros. Dessa maneira, analisamos os livros: $O$ Menino Nito: Então, Homem Chora ou Não?, de Sonia Rosa (2002); Minha Mãe é Negra Sim, de Patricia Santana (2008); Minha Família é Colorida, de Georgina Martins (2005); Chico Juba, escrito por Gustavo Gaivota (2011); e Cabelo de Mola, de Alexsander Rezende (2012). Partimos do pressuposto que no campo das relações étnico-raciais há questões de gênero que precisam ser estudadas. Ser menino e negro é diferente de ser menina e negra. Assim, a partir do conceito de masculinidades negras buscamos retratar nas narrativas os elementos que fortalecem e desconstroem os estereótipos associados à identidade de meninos e negros, desde a infância. Os dados evidenciaram a importância de atentar para as construções discursivas que reforçam estereótipos, desde a infância, de meninos e negros como brutos, pouco inteligentes e servis, e, ainda, fortalecem o mito da democracia racial.

Palavras-chave: literatura infantil; relações étnico-raciais; masculinidade negra; Educação Infantil.

\section{ABSTRACT \\ BEING A BLACK BOY: AN ANALYSIS IN CHILDREN'S LITERATURE BOOKS}

This paper focuses on the analysis of children's literature books that have black boys as their protagonists. Thus, we analyzed the books: $O$ Menino Nito: Então, Homem Chora ou Não? (The boy Nito: So, does a man cry or not?) by Sonia Rosa (2002); Minha Mãe é Negra Sim (My mother is black) by Patricia Santana (2008); Minha Família é Colorida (My family is colorfully) by Georgina Martins (2005); Chico Juba by Gustavo Gaivota (2011); and Cabelo de Mola (Spring Hair) by Alexsander Rezende (2012). We start from the assumption that in the

Doutora em Educação pela Universidade Federal da Paraíba (UFPB). Professora adjunta da Universidade de Pernambuco (UPE), Recife, Pernambuco, Brasil. E-mail: tarcia.silva@upe.br

** Doutor em Psicologia Cognitiva pela Universidade Federal de Pernambuco (UFPE). Professor Permanente do Programa de Pósgraduação em Formação de Professores e Práticas Interdisciplinares da Universidade de Pernambuco (PGFPPI/UPE), Petrolina, Pernambuco, Brasil. Pró-Reitor de Graduação da Universidade de Pernambuco (UPE). E-mail: ernani.santos@upe.br 
field of ethno-racial relations there are gender issues that need to be studied. Being a boy and black is different from being a girl and black. Thus, based on the concept of black masculinities, we sought to portray in the narratives the elements that strengthen and deconstruct the stereotypes associated with the identity of boys and black men, since childhood. The data showed the importance of paying attention to the discursive constructions that reinforce stereotypes, from childhood, of boys and black men as brutes, not very intelligent, servile, and also strengthen the myth of racial democracy.

Keywords: children's literature; ethno-racial relations; black masculinity; Childhood Education.

\section{ABSTRACT \\ SER UN NIÑO NEGRO: UN ANÁLISIS EN LOS LIBROS DE LITERATURA INFANTIL}

Este artículo se centra en el análisis de libros de literatura infantil que tienen como protagonistas a niños negros. Así, analizamos los libros: O Menino Nito: Então, Homem Chora ou Não? (El niño Nito: Entonces, ¿un hombre llora o no?) de Sonia Rosa (2002); Minha Mãe é Negra Sim (Mi madre es negra) de Patricia Santana (2008); Minha Família é Colorida (Mi familia está escrita de manera colorida) escrito por Georgina Martins (2005); Chico Juba escrito por Gustavo Gaivota (2011); y Cabelo de Mola (Cabello con rizos) de Alexsander Rezende (2012). Partimos de la base de que en el ámbito de las relaciones étnico-raciales existen cuestiones de género que deben ser estudiadas. Ser un chico y negro es diferente a ser una chica y negra. Así, a partir del concepto de masculinidades negras se busca retratar en las narrativas los elementos que fortalecen y deconstruyen los estereotipos asociados a la identidad de los niños y de los negros, desde la infancia. Los datos mostraron la importancia de prestar atención a las construcciones discursivas que refuerzan los estereotipos, desde la infancia, de los niños y de los negros como brutos, poco inteligentes, serviles y también refuerzan el mito de la democracia racial.

Palabras clave: literatura infantil; relaciones étnico-raciales; la masculinidad negra; Educación infantil.

\section{Para início de conversa}

Neste artigo, partimos do princípio da literatura como direito humano (CANDIDO, 2011, p. 172), salientando que "aquilo que consideramos indispensável para nós é também indispensável para o próximo". Nesse sentido, questionamos: quem nunca desejou se deparar com uma história cujas imagens dos personagens se assemelhassem consigo? Que menino e negro, ou que menina e negra, não desejou se ver representado em um livro de literatura infantil e/ou juvenil? Dessa maneira, reconhecemos o quanto é significativo fomentar a representação da população negra nos livros de literatura infantil e juvenil.

E, tal fato vem ocorrendo após a promulgação das Leis $\mathrm{n}^{0} 10.639$ (BRASIL, 2003) e $\mathrm{n}^{\mathrm{o}}$ 11.645 (BRASIL, 2008). De acordo com Debus (2017), o mercado editorial, em sintonia com as referidas leis, tem aumentado o número de títulos que dialogam com a cultura afro-brasi- 
leira e africana. Contudo, segundo essa autora, não devemos entender esse aumento apenas pelo viés mercadológico, que visa o reconhecimento de um nicho com vistas ao lucro. A obrigatoriedade do ensino da cultura africana e afro-brasileira, o compromisso de algumas redes de ensino e de professores, o aumento de pesquisas e os movimentos sociais podem ser alguns elementos, entre outros, que estão cooperando para a propagação de títulos literários com a temática étnico-racial.

Entretanto, de acordo Araújo e Silva (2012), a representação da população negra na literatura ainda oscila entre a não representação e a apresentação de forma racista e estereotipada. Nesse contexto, entendemos que os elementos que compõem os textos literários podem propiciar, a partir da sua narrativa, a construção de elementos positivos para a valorização da identidade da criança e negra, desde a infância.

Em articulação com esses argumentos, salientamos a relevância dessa discussão para a infância e, particularmente, para a Educação Infantil, uma vez que acreditamos que a escola tem um papel importante para cumprir nesse debate, pois a diversidade étnico-racial perpassa a nossa sociedade e invade as creches e pré-escolas através de "modelos estético-corpóreos e culturais, elementos constitutivos da identidade de bebês e crianças pequenas que sob nenhuma hipótese podem ser ignorados, subestimados ou negligenciados pela política educacional" (SILVA JÚNIOR, 2012, p. 69).

Ainda de acordo com Silva Júnior (2012), embora haja um aumento da preocupação com as orientações para professores e gestores sobre a diversidade étnico-racial na Educação Infantil, as ações desenvolvidas discorrem em um erro, pois estão centradas na perspectiva da adoção de uma postura reativa, repressiva da discriminação e do preconceito, quando a Educação Infantil pode fazer muito mais. Ela pode preparar as crianças para a valorização da diferença étnico-racial e para a construção de uma sociedade igualitária. Para tal, esse autor aponta duas possibilidades: a primeira trata da garantia de um ambiente em que as relações se dão de forma positiva e respeitosa, o que exige a readequação do espaço escolar no sentido de repensar os espaços físicos, os materiais e livros didáticos e de literatura; o segundo,

[...] situa a educação infantil como instrumento de transformação social no sentido em que prepara a infância para valorar positivamente a diferença, dissociando diferença de inferioridade de tal sorte que a médio e longo prazo o preconceito e a discriminação sejam erradicados da sociedade. (SILVA JÚNIOR, 2012, p. 71).

Logo, não basta que a educação infantil não seja ela mesma, através das suas práticas pedagógicas, uma fonte de discriminação; competelhe também fomentar uma cultura de respeito, valorização e celebração das diferenças.

A partir desse pressuposto, apresentamos uma pesquisa documental a partir da análise de cinco livros de literatura infantil que trazem na construção da sua narrativa meninos negros na contemporaneidade. Tal premissa está ancorada na perspectiva de que há especificidades de gênero dentro da discussão das relações étnico-raciais que precisam ser consideradas. Consequentemente, "ser menino e negro é diferente de ser menina e negra" (SILVA, 2015, p. 160). A partir dos conceitos de interseccionalidade e de masculinidades negras, nos propomos a retratar os elementos que fortalecem e desconstroem estereótipos e modos subalternos de ser e existir dos meninos e negros nas obras analisadas.

Explicitamos que assim como Abramowicz, Oliveira e Rodrigues (2010), consideramos legítimo discutir a criança negra não como uma categoria essencializada, que legitima uma visão que apenas "pensa a criança"; precisamos organizar nossos esforços numa abordagem que "vê uma criança", considerando-a não mais a partir de uma perspectiva universal, mas numa perspectiva singular. "Uma criança e negra é um esforço de tornar compossível pensar raça, gênero, sexualidade e classe social, como categorias minoritárias" (ABRAMOWICZ; OLIVEIRA, 2012, p. 51). Assim, precisamos 
evidenciar a criança como sujeito social que, ao mesmo tempo em que se forma, é também formado na trama das relações sociais, constituindo-se a partir dessas relações uma criança e negra.

Nessa direção, o nosso objetivo é discutir como os efeitos das narrativas analisadas podem incidir na constituição da identidade dos meninos e negros, pois concebemos os livros de literatura como importantes instrumentos na construção da identidade da criança, considerando a representatividade dos personagens, principalmente protagonistas, como modelos de inspiração e identificação para os bebês, crianças bem pequenas e crianças pequenas.

Nessa tessitura, escolhemos os títulos: $\mathrm{OMe}$ nino Nito: Então, Homem Chora ou Não?, de autoria de Sonia Rosa (2002), com ilustrações de Victor Tavares; Minha Mãe é Negra Sim, de Patricia Santana (2008), com ilustrações de Hyvanildo Leite; Minha Família é Colorida, escrito por Georgina Martins (2005) e com ilustrações de Maria Eugênia; Chico Juba, de Gustavo Gaivota (2011), com ilustrações de Rubem Filho; e Cabelo de Mola, que tem Alexsander Rezende (2012) como autor e ilustrador.

\section{Os meninos e negros nos livros de literatura infantil: reflexões, tensões e resistências}

Em consonância com Candido (2011, p. 174), compreendemos que literatura representa "todas as criações de toque poético, ficcional ou dramático em todos os níveis de uma sociedade, em todos os tipos de cultura [...]". É o referido autor que nos explica ainda que a literatura pode ser considerada "o sonho acordado das civilizações" (CANDIDO, 2011, p. 175). Para ele, se não há equilíbrio psíquico sem o sonho durante os nossos sonos, também não há equilíbrio social sem a literatura. Assim, a literatura é um fator primordial para a nossa humanização. Nesse contexto, ressaltamos a importância de narrativas que valorizem a identidade da população negra considerando que as desigualdades raciais ainda perduram na nossa sociedade. Dessa maneira, oportunizar que crianças e negras, bem como as não-negras, possam conhecer essas histórias é contribuir para uma sociedade equânime.

Nesse sentido, para Debus (2017), os títulos que conhecemos no campo da literatura infanto-juvenil que tratam das relações étnico-raciais estão agrupados em três categorias: literatura que tematiza a cultura africana e afro-brasileira; literatura afro-brasileira; literaturas africanas. Na primeira categoria, temos o grupo de histórias que têm como foco o tema, e não o autor. Na segunda, leva-se em consideração quem escreve, são obras de escritores afro-brasileiros. Já a terceira categoria tem a sua centralidade na produção africana, que se desdobra em subcategorias de acordo com o país ou língua de origem.

Para Kirchof, Bonin e Silveira (2015), que fizeram uma análise de vinte e duas obras de literatura infantil, há três tendências principais por meio das quais a abordagem da temática étnico-racial é realizada. $\mathrm{Na}$ primeira tendência, o principal instrumento narrativo é a vivência de conflitos que envolvem atos de preconceitos ou de discriminação racial. Em geral, há a participação de um adulto, alguém mais velho ou mais experiente para orientar o/a protagonista. Assim, a diferença étnico -racial é vivenciada por meio "de situações 'ficcionalizadas' de racismo, as quais devem ser esclarecidas e ultrapassadas, apontandose, ao leitor, uma clara lição de fraternidade e/ou aceitação" (KIRCHOF; BONIN; SILVEIRA, 2015, p. 393). Numa segunda abordagem, para esses autores, a população negra entra em cena em episódios cotidianos sem que a questão racial seja a discussão proposta. Assim, a sua presença é observada através das ilustrações. Já a terceira tendência trata a discussão de forma celebratória. Nota-se uma "multiplicação de livros, nos últimos anos, que pretendem 'ensinar', aos jovens leitores, a atitude correta e desejável em relação ao outro" (KIRCHOF; 
BONIN; SILVEIRA, 2015, p. 406). Dessa forma, os autores concluem que:

Apesar das diferenças quanto ao modo como essa temática tem sido abordada, permanece o estreito enlace entre os intuitos pedagógicos e a literatura (com ou sem aspas) que se oferece às crianças leitoras do século XXI. Tal enlace se torna, hoje, muito evidente nos livros que buscam explanar sobre a diversidade e, a partir de tal abordagem, procuram colocar em discussão o preconceito étnico-racial e promover atitudes respeitosas para com as diferenças. (KIRCHOF; BONIN; SILVEIRA, 2015, p. 410).

Nesse contexto, analisar a interseccionalidade entre raça e gênero "é perguntar como devemos discuti-la a partir de um olhar relacional, e não posicional e hierárquico fixo" (CONRADO; RIBEIR0, 2017, p. 82). A interseccionalidade nos desperta para a premissa de que o mundo que nos cerca é bem mais complicado e contraditório do que podíamos pensar inicialmente. Para Crenshaw (2002), as interseccionalidades são construídas para que possamos refletir sobre as consequências da influência mútua entre duas ou mais formas de dependência. Assim, esse conhecimento de complementariedade entre formas de sujeição nos ajuda a evidenciar a superposição de opressões. Nesse contexto, a interseccionalidade representa a abordagem e análise da problemática a partir de diversos caminhos, em que cada um deles é rodeado por eixos de opressão. Nesse sentido, buscamos focar no menino e negro protagonista das histórias apresentadas para entender o lugar destinado a ele como menino, como negro e como menino e negro.

Dessa maneira, iniciamos pela análise do livro O Menino Nito (ROSA, 2002), situado na segunda tendência de livros de literatura infantil, que tratam da temática étnico-racial apresentada por Kirchof, Bonin e Silveira (2015), pois não há a priori uma discussão racial. Dessa maneira, percebemos a presença dos personagens negros através das ilustrações. 0 enredo da história versa sobre o choro de Nito, ou seja, ele trata do choro de um menino e negro. De acordo com Connel e Messerschmidt (2013, p.
245), a masculinidade hegemônica "incorpora a forma mais honrada de ser um homem", e essa forma pode ser associada à negação da dor, do choro. Assim, Nito é aquele que não pode chorar, aquele que precisa calar a sua dor. Já na capa, Nito nos é apresentado tentando segurar uma parede para que ela não desabe, pois está vazando, tendo as suas pernas submersas em suas lágrimas, ao lado de um intrigante questionamento: Então, homem chora ou não?

Ao iniciarmos a leitura do livro descobrimos que o menino protagonista da história ganhou o nome de Nito devido ao reconhecimento da sua beleza ao nascer, todos o chamavam de Bonito. Em razão disso, ficou conhecido como Nito. Nasceu aparentemente numa família de classe média e também parece ser filho único. Entretanto, a narrativa logo aponta que o menino tinha um probleminha: "chorava por tudo" (ROSA, 2002, p. 4). Desde a infância os meninos são orientados a engolir o choro. Comumente ouvem que homem não chora. De acordo com Connell (1995, p. 190), "toda cultura tem uma definição de conduta e dos sentimentos apropriados para os homens". Dessa forma, os meninos são forçados a agir e a viver se distanciando de comportamentos que naquela sociedade são associados ao comportamento feminino. Dessa maneira, o pai, do não mais tão pequeno Nito, o orienta: “- Nito, meu filho, você está virando um rapazinho... já está na hora de parar de chorar. E tem mais: homem não chora! Você é macho! Acabou o chororô de agora em diante, viu?" (ROSA, 2002, p. 5).

0 fato de uma criança negra ser o personagem principal de 0 menino Nito nos faz pensar que, se o choro já seria uma temática difícil de ser abordada no campo literário em relação ao gênero masculino, o choro de um menino negro se configura como algo completamente novo, pois a dor e o sofrimento de meninos e meninas negras e de suas famílias são completamente ignorados ainda hoje pelo Estado brasileiro (como exemplo, o choro das famílias Ágatha, de 8 anos, e João Pedro de 14 anos, vítimas da violência policial no Rio de Janeiro (NASCIMENTO; SILVA, 2020, p. 222). 
Acrescentamos a esse choro engolido, o choro de Miguel, criança recifense de cinco anos que caiu do nono andar de um condomínio de luxo, enquanto estava sob os cuidados da patroa de sua mãe. Na ocasião, Mirtes, uma empregada doméstica, tinha saído para passear com a cadela dos patrões. Retomando a narrativa, observamos que a partir da postura do pai que chama a criança no canto para inibi-la, reforçando a imagem do homem e negro como bruto, grosseiro, pouco amoroso, a narrativa de $O$ Menino Nito (ROSA, 2002) denuncia a violência familiar a que as crianças estão sujeitas. Entretanto, ao pensarmos a questão da masculinidade negra, o episódio destaca, entre outros aspectos, a virilidade e a truculência como agentes que perfazem o modelo social através do qual o homem negro é visto (HOOKS, 2004). Logo, para ser macho, menino não chora! Segundo Nkosi (2014, p. 91), “o homem negro deve ser macho ao quadrado em todas as situações exigidas, e só a partir destes atributos será reconhecido".

Assim como Hooks (2018), reconhecemos que os meninos são orientados desde cedo a não demonstrarem as suas emoções, sobretudo quando estas as fazem sofrer, sob o risco de se tornarem menos homem ao fazê-lo. Dessa maneira, acabam omitindo as suas dores, sofrimentos, angústias, tormentos, sendo a melhor resposta para quando esses sentimentos vierem à tona "empurrá-los goela abaixo, esquecê-los, esperar que vão embora (HOOKS, 2018, p. 3). É sob essa perspectiva que meninos vão sendo educados na nossa cultura e estabelecendo formas de ser e existir. Assim, ser homem "é também aprender a respeitar os códigos, os ritos que se tornam então operadores hierárquicos" (WELZER-LANG, 2001, p. 463).

Entretanto, Connell (1995, p. 190) nos alerta que "esforçar-se de forma demasiadamente árdua para corresponder à norma masculina pode levar à violência ou à crise pessoal e a dificuldades nas relações". É exatamente o que acontece com Nito. As ilustrações que acompanham essa passagem na história são muito interessantes. Ele vai construindo um muro que vai represando o seu choro. Não expressa as suas emoções e adoece um pouco a cada choro engolido. Frente a esse cenário, a família resolve chamar o Doutor Aymoré, "um velhinho simpático que sempre cuidou de plantas e crianças" (ROSA, 2002, p. 10). 0 médico, também um homem negro, desvela logo a solução; após ouvir o Menino Nito, pede para que a mãe dele pegue duas bacias grandes, lhe oferece $o$ seu colo e solicita que ele se lembre de todos os choros engolidos e os coloque para fora. Após essa solicitação, Nito indaga o médico:

- Eu posso? Mas, eu não sou homem?

- Exatamente porque você é homem é que não pode engolir os choros. Todo homem tem lágrimas e as lágrimas são para rolar pelo rosto. Qualquer rosto: de um homem, mulher, criança e gente de idade. Agora vamos parar de papo furado e comece logo a desabrochar! (ROSA, 2002, p. 11).

Assim, autorizado pelo médico, Nito solta o seu choro, que assusta a vizinhança pela quantidade, emociona seus pais e também o médico. No mesmo dia, o pai o chama novamente e reflete:

- Filho, você deve chorar sempre que quiser, mas não chore sem razão. Acho que agora aprendemos a lição: Chorar é bom. Às vezes deixa a gente mais homem. [...] Os dois se abraçaram forte. Ficaram assim um tempão... Um sentindo a batida coração do outro... (ROSA, 2002, p. 14).

O desfecho apresentado pela autora pode contribuir para que os meninos, sobretudo os meninos e negros, se vejam representados, bem como encontrem um alento, um colo para acalentar os seus choros engolidos por motivos de violência aos quais são expostos dentro e fora das suas casas. Ao apresentar a ressignificação dessa relação entre pai e filho, se oportuniza ao pai rever a sua postura autoritária, reconhecendo, assim, a necessidade de destinar afeto, carinho, atenção e cuidado ao seu filho, favorecendo a desmistificação do estereótipo de homem rude associado ao homem e negro. 
A segunda história que apresentamos é Minha Família é Colorida, escrita por Georgina Martins (2005) e ilustrado por Maria Eugênia. Ela traz como personagem principal um menino negro muito curioso, o Ângelo, que certo dia faz indagações a sua mãe acerca de seu cabelo: "Mãe, o meu cabelo não 'vua', o da minha vó Marli 'vua', o seu 'vua', o do Camilo 'vua' um pouco, e o do meu pai não. Sabe por quê? Meu pai passou cola no meu cabelo e no dele também" (MARTINS, 2005, p. 8). Dessa maneira, Ângelo começa, a partir da questão do cabelo, a problematizar a questão racial e as diferenças existentes entre os integrantes da sua família. De acordo com ele, uns cabelos "vuam" e outros não. As indagações de Ângelo refletem o que nos aponta Fanon (2008, p. 104): “[... no mundo branco, o homem negro encontra dificuldade na elaboração de seu esquema corporal. 0 conhecimento do seu corpo é unicamente uma atividade de negação. É um conhecimento em terceira pessoa."

Para Silva (2015), os meninos e negros, desde a sua infância, têm uma beleza negada. Nessa tessitura, enquanto as meninas são incentivadas socialmente, e também na escola, a desenvolverem uma variedade de penteados e a usarem artefatos para o enriquecimento da sua imagem, aos meninos resta o cabelo raspado, com máquina, bem baixinho. De acordo com Amaral (2013, p. 175-176), “[...] com o intuito de discipliná-los e/ou moldá-los de modo mais similar ao pertencimento racial do grupo branco, os meninos perdem os cabelos, resolvendo assim de modo mais fácil a necessidade de aceitação e assimilação da norma branca".

Entratanto, os questionamentos de Ângelo não findam com a questão do cabelo, e ele indaga novamente à mãe: "Mãe, eu sou negro?" (MARTINS, 2005, p. 11). Ser negro, no Brasil, além de designar o indivíduo deste grupo étnico-racial, pode significar: sujo, funesto, sinistro, maldito, perverso, triste, nefando etc. São essas as definições apontadas pelos mais importantes dicionários da nossa língua. Assim, o negro é aquele que não se deseja ser. Refletindo acerca da contextura brasileira, de acordo com Souza (1983), a sociedade escravocrata reduziu o africano a escravo, estabeleceu a cor como raça, fazendo com que ela definisse o lugar, a condição de tratamento, a forma de socialização com o branco, e consolidou o correlato entre a negritude e a posição inferior na sociedade.

Silva (2015), ao questionar meninos e meninas entre quatro e cinco anos de um Centro Municipal de Educação Infantil do Recife sobre ser negro, evidenciou que, para os meninos, ser negro é mais difícil. São eles que compõem o grupo dos mais marginalizados, pois ocupam um longínquo lugar dos padrões inventados e preservados pela hegemonia da masculina branca. Apresentam uma identidade da qual gostariam de manter distância. De acordo com Silva (2006), em todas as sociedades ocidentais há um modelo de masculinidade socialmente valorizado, e esse modelo a que os pesquisadores chamam de masculinidade hegemônica é formado pelo ideal do homem branco, heterossexual e burguês. Ao perguntar a sua mãe se é negro, provavelmente Ângelo reconhece que como menino e negro, "vive numa sociedade marcada pelas diferenças, e a diferença que traz no seu corpo, a sua cor, marca a desigualdade de tratamento a ela destinado" (SILVA, 2015, p. 156).

Diante do questionamento de Ângelo, sua mãe começa a explicá-lo sobre a sua história familiar, tentando justificar porque ele é "bem moreno", segundo a sua heteroatribuição. De acordo com Debus (2010, p. 203), "o uso de tal termo, característica de um vocábulo permeado pelo preconceito, traz, mesmo que de forma ingênua, marcas de discriminação" na obra. Nessa perspectiva, a mãe retoma a história da constituição da família de Ângelo explicitando como, desde os seus tataravôs, a miscigenação entre brancos e negros se fez presente na sua família. A narrativa assume, assim, a perspectiva da diversidade e não da diferença. Logo, as relações de poder envoltas na discussão do processo de miscigenação no Brasil são ocultadas. Há muita desigualdade 
no tratamento, nos diferentes espaços sociais, entre as crianças que têm cabelo que "vua" e cabelo que não "vua". Desigualdade de tratamento e oportunidades, desde a infância, entre população negra e não-negra. De acordo com Debus (2010, p. 202):

0 texto trabalha a miscigenação das diferentes etnias, porém, embora a nossa formação histórica seja caracterizada pela miscigenação étnica, racial e cultural, faz-se necessário um olhar cuidadoso e atento ao nos aproximarmos dessa questão. 0 contexto histórico, que envolve essa característica nacional, origina-se da dominação e da exploração do trabalho escravo. A ideia de nação mestiça, no Brasil, é resultado de um processo colonizador violento, e não apenas da relação amistosa entre as raças.

Na análise de Munanga (2004), o mestiço brasileiro vive uma ambiguidade que se torna fatal na hora de definir sua identidade, pois, desde o início da história do Brasil, ele tem uma identidade indefinida que, aliada ao ideário do embranquecimento, dificulta tanto a afirmação da sua identidade mestiça, quanto a de sua identidade negra, ficando, assim, a afirmação da identidade negra adiada, esperando um dia ser branco, pela miscigenação e/ ou ascensão social. Da forma como a questão é situada no texto, Ângelo pode vir a inferir que se casando com uma mulher branca, ele pode vir a ter filhos mais claros como o seu irmão, por exemplo. Logo, os cabelos de seus filhos podem "vuar",

Com base em tal peculiaridade, ao classificar Ângelo como "bem moreno", é que atentamos para as reflexões que podem emergir em função da literatura infantil, pois a narrativa perdeu uma fortuita oportunidade de reconhecer que na categoria de meninos negros também estão os meninos pardos e não apenas os pretos. Assim, oferecer referências que ajudem a criança no entendimento desse lugar de pardo como também negro é uma questão primordial. Os elementos estético-corpóreos, tanto no texto quanto nas ilustrações, que são destacados com maior ênfase são os cabelos e a cor dos olhos, conforme descrição abaixo:
Dizem que o pai do pai do pai do Ângelo se apaixonou pela cor da pele da mãe do pai do pai do Ângelo, que era negra como a noite. [...] A avó Marli conta que se apaixonou pelos cabelos do avô Agostinho, que eram, como os seus, todos enroladinhos [...] E ela se apaixonou pelos olhos do avô Edilson, verdes como as ondas do mar. (MARTINS, 2005, p. 16-31).

Essas passagens apresentadas no livro evidenciam que o corpo e o cabelo são elementos importantes na construção da identidade da criança e negra. Dessa maneira, a mãe de Ângelo faz uso de comparações entre a cor dos olhos e o cabelo com elementos da natureza para explicar para ele a questão em voga. Para Kirchof, Bonin e Silveira (2015, p. 398), a estratégia de estabelecer paralelos entre os integrantes da família e elementos da natureza "serviria para neutralizar, de certa forma, as relações de força implicadas na definição cultural do que é "ser igual" ou "ser diferente", reforçando a discussão dentro do campo da diversidade".

A partir dessa perspectiva, a história apresenta como desfecho: "Mãe, então sabe por que meu cabelo não 'vua' e a minha pele é assim, dessa cor? É porque a nossa família é toda colorida, eu acho que ela é muito bonita, igualzinha à minha caixa de lápis de cor!" (MARTINS, 2005, p. 39). De acordo com Rodrigues e Abramowicz (2013, p. 17), ao situar a discussão das relações étnico-raciais a partir da diversidade, corremos o risco de delimitar a questão "ao simples elogio às diferenças, pluralidades e diversidades, tornando-se uma armadilha conceitual e uma estratégia política de esvaziamento e/ou apaziguamento das diferenças e das desigualdades". Assim, a cor/raça, o corpo e o cabelo, elementos identitários do menino e negro apresentados como mote na história Minha Família é Colorida (MARTINS, 2005), pode acabar reforçando o mito da democracia racial.

0 terceiro livro analisado é Cabelo de Mola, de Alexsander Rezende (2012), que nos conta a história de Eduardo, "um menino que adora todas as brincadeiras, mas a sua favorita é futebol" (REZENDE, 2012, p. 4). Ele e sua família se mudaram para um novo bairro. Assim, Eduardo 
estava muito ansioso para conhecer os novos vizinhos/colegas. Entretanto, um dia após a sua mudança, "aconteceu algo lamentável! Todos olharam feio e desprezaram Eduardo por ele ser negro" (REZENDE, 2012, p. 6). É assim que o autor apresenta a problemática da narrativa. Qual o problema de ser menino e negro? 0 que faz com quem Eduardo seja rejeitado pelos novos vizinhos? "Minha negrura era densa e indiscutível. Ela me atormentava, me perseguia, me perturbava, me exasperava." (FANON, 2008, p. 109).

Sem fazer rodeios, nem sequer colocar a ludicidade em jogo, Rezende (2012) aponta que é por causa da sua cor que Eduardo não pode se inserir no novo ambiente. As ilustrações reforçam os atos de discriminação racial sofridos, mostrando as crianças brincando e olhando com cara de zangadas para Eduardo, que vai embora aos prantos. Certamente, essa cena é vivenciada por muitas crianças e negras ainda hoje, que assim como o personagem da história, choram para extravasar a sua dor. De acordo com Fanon (2008), o universo branco estava negando a sua participação. Dessa maneira, exigia-se de Eduardo uma conduta diferente da que se exige de qualquer menino, exigia-se dele a "conduta de homem negro - ou pelo menos uma conduta de preto. Eu acenava para o mundo e o mundo amputava meu entusiasmo. Exigiam que eu me confinasse, que encolhesse" (FANON, 2008, p. 107). É sob essa lógica narrativa que a história vai sendo construída, o que pode repercutir de maneira muito negativa na construção da identidade do menino e negro, bem como para os não-negros.

A história apresenta ainda as várias tentativas de Eduardo de se aproximar dos colegas. As ilustrações o apresentam oferecendo bolinhas de gude, bicicleta, pipa, mas todos os seus esforços são frustrados, não obtendo a atenção dos meninos não-negros. É como bom e servil menino negro que o autor apresenta as estratégias de Eduardo para fazer amizade com os demais. Coloca-o como historicamente sempre se foi destinando espaços subalternos à população negra. "Em cada tentativa, cabialhe provar espontaneamente, a si próprio e ao branco, por palavras gestos e ações, o caráter simétrico de suas relações, anulando-se como pessoa, como se não fosse e nunca pudesse ser gente" (FERNANDES, 2008, p. 366).

Há na narrativa um reforço do sujeito na sua capacidade de obediência, de sujeição à vontade do outro. A subalternidade na narrativa representa o caminho escolhido para ser aceito, incluso. É nessa condição servil que o menino negro ocupa espaço no coração dos outros, de acordo com a proposta do livro. 0 sujeito anula-se, diminui-se e se coloca numa situação desigual.

0 autor apresenta ainda o futebol como elemento para a aceitação de Eduardo. Nessa conjectura, ele foi convidado para participar de uma partida, e como tinha habilidade, fez o gol mais bonito do jogo. "Para a alegria de Eduardo, todos festejaram e o abraçaram com satisfação. A partir daquele momento, Eduardo começou a ser visto com outros olhos." (REZENDE, 2012, p. 6). A construção desse desfecho coaduna e reforça a ideia de que é o corpo negro que entre em cena, não Eduardo na sua integralidade como sujeito, como humano, mas como potência corporal que, ao estar do lado dos vizinhos, lhes assegura a vitória no jogo de futebol. Não é parceria. É troca. Jogando bola, ele passa a ser um menino negro benquisto da rua. É ele, ainda, um negro da casa grande que se conserva no lugar da submissão.

Eduardo é visto como um objeto, podendo ser descartado a qualquer tempo. Para Fanon (2008), ao desconhecer a humanidade do outro, ou seja, os meninos brancos, ao negarem a Eduardo a sua amizade por causa da sua cor, negam também a eles mesmos a condição de ter um corpo, o que os faz serem brancos incompletos. Assim, para preencher essa ausência, eles desejam o outro, mas como subalterno, como jogador de futebol. Nesse caso, negando Eduardo socialmente como humano. Esse percurso segregador é seguido milimetricamente na narrativa em voga. 
Nesse sentido, o enredo da história desconsidera os efeitos e sentidos da generalização do menino e negro como apenas um corpo, enquanto aos meninos brancos estão associados os elementos da razão, pois é conscientemente que eles rejeitam a cor/raça de Eduardo. Dessa forma, os meninos não negros, desde a infância, vão criando brechas nas quais fazem com que os meninos negros acreditem que estão plenamente respeitados e acolhidos, o que os interdita de perceber a sua situação de prisioneiro do seu corpo nas hierarquias instituídas pelo opressor, no caso, pelos vizinhos. Assim, desde criança reconhecemos que "ser negro é ser violentado de forma constante, contínua e cruel, sem pausa ou repouso" (GOMES, 2006, p. 68), inclusive através dos livros de literatura infantil.

A nossa quarta história é a de Chico Juba, que tem texto de Gustavo Gaivota (2011) e ilustrações de Rubem Filho. Ela se inicia apresentando o personagem principal através da ilustração e também do texto: "Chico Juba tem uma cabeleira que só vendo; deixa muita gente verdejando de inveja. Mas durante muito tempo quis que seu cabelo fosse diferente: virou até inventor" (GAIVOTA, 2011, p. 3). Nesse contexto, as suas invenções são estratégias para mudar o seu cabelo. A história mostra Chico Juba na atualidade e vai retrocedendo e mostrando as suas invenções para mudar o cabelo. Logo, o pressuposto inicial é de que ele não está satisfeito com a sua cabeleira. Contudo, precisamos entender que não é apenas o cabelo que ele nega. Ao negá-lo, nega também a sua cor/raça. Assim:

Cabe esclarecer que o termo raça é utilizado com frequência nas relações sociais brasileiras, para informar como determinadas características físicas, como cor de pele, tipo de cabelo, entre outras, influenciam, interferem e até mesmo determinam o destino e o lugar social dos sujeitos no interior da sociedade brasileira. (BRASIL, 2004, p. 13).

Através da narrativa também se faz uma importante denúncia, mesmo de maneira subliminar, aos tratamentos estéticos aos quais a população negra precisa se submeter para atingir o ideal de beleza do branco. Ao apresentar esses percalços sendo vivenciados por um menino, o texto traz uma importante contribuição para a discussão sobre os elementos estético-corpóreos da identidade do menino e negro. Em geral, as discussões sobre o cabelo nos livros de literatura infantil estão centradas na identidade da menina e negra. Nessa busca pelo ideal de beleza branco, eurocêntrico, Chico Juba faz vários experimentos:

Certa vez, inventou um xampu feito de dentese leão [...]. Desta vez, quis inventar um xampu mais discreto, feito à base de sabão de coco. [...] De outra feita, encomendou terra roxa de um agricultor paulista muito respeitado na Internet [...]. Seus últimos eventos foram desastrosos. 0 xampu de água de bateria foi eletrizante que dava choque em todo mundo! 0 xampu de pó de ouriço deixou seus cabelos duros e espetados. (GAIVOTA, 2011, p. 4-17).

Evidentemente que cada uma dessas tentativas terminou em desastre. De acordo com Gomes (2002), o corpo e o cabelo são significados pela cultura. Assim, eles podem ser pensados como formas de expressão e de aparatos simbólicos da identidade da população negra. "Juntos, eles possibilitam a construção social, cultural, política e ideológica de uma expressão criada no seio da comunidade negra: a beleza negra" (GOMES, 2002, p. 2). É importante salientar que não estamos partindo do pressuposto da não manipulação do cabelo da forma que cada um desejar, estamos destacando as formas agressivas de manipulação do cabelo que geram danos físicos e também mentais, como podemos evidenciar nesse trecho da história: "Seus cabelos estavam tão leves e tão soltos que, quando soprou o vento norte, todos os fios de sua cabeleira esvoaçaram ao vento. Foi assim que ele ficou careca pela primeira vez" (GAIVOTA, 2011, p. 5).

Há também um episódio ao longo da história que destaca a compra de Chico de "um xampu de mulher" (GAIVOTA, 2011, p. 18), considerando que as mulheres são mais exigentes no trato com o cabelo. Entretanto, após o seu uso, a "sua voz ficou fina e suave, como a de uma 
mulher" (GAIVOTA, 2011, p. 19). Nessa construção narrativa, observa-se que o autor busca dar visibilidade ao erro cometido pelo menino, pois para ser visto e aceito, sobretudo como menino e negro, é necessário que ele se apresente como truculento e/ou agressivo, que dispense o trabalho intelectual, o que foi explicitado pelas inúmeras tentativas frustradas de mudar o cabelo (HOOKS, 2004). Não podendo de nenhuma maneira ficar com "voz de mulherzinha", como evidencia a narrativa: "sem dúvida ficou com uma voz muito agradável, mas não combinou com seu estilo" (GAIVOTA, 2011, p. 19).

No contexto das discussões de gênero, esse argumento considera uma premissa que pouco contribui para as discussões da infância e da diferença "menino veste azul, menina veste rosa". A partir de ponderações como as apresentadas no texto, os meninos e as meninas vão se construindo como masculinos ou femininos, arranjando e desarranjando seus lugares sociais, suas disposições, suas formas de estarem no mundo. Nesse sentido, a distinção hierárquica entre masculino e feminino, a separação entre coisas, brincadeiras, cores, entre outras questões, fortalece o aspecto biológico. Quando essas narrativas são propostas para as crianças desde a Educação Infantil, elas podem contribuir para novas construções e desconstruções de imagens de gênero, proposições e concretizações de alterações de hierarquias, fazendo com que cada um de nós, sobretudo as crianças, possa repensar de maneira lúdica sobre os "scripts de gênero" (ZANETTE; FELIPE, 2017). 0 episódio como esse supracitado no livro desconsidera:

[...] a existência de diferentes configurações da prática de gênero, ocultando a existência de masculinidades que não se percebem a partir da virilidade e da truculência e que assumem fragilidades e vulnerabilidades, mesmo que vivenciem privilégios e microbenefícios oriundos do sexismo. (CONRADO; RIBEIRO, 2017, p. 84).

Por fim, "depois de tantas aventuras, Chico Juba resolveu aceitar o seu cabelo do jeito que ele é. Por isso que hoje ele parou de inventar xampus e passou a inventar moda!" (GAIVOTA, 2011, p. 19). No seu desfecho, as ilustrações mostram Chico Juba bem sorridente, vibrante e com vários modelos de penteados. Esta narrativa nos faz relembrar uma polêmica na novela Amor à Vida, de 2013, da Rede Globo, que tinha um personagem menino e negro com um cabelo black bem grande, cujo corte foi solicitado pelo autor da novela, que deu o seguinte depoimento:

Lutar contra o preconceito é mostrar que um personagem branco pode adotar um menino negro e ser feliz. Eu acho o cabelo black lindo. Mas nenhum menino num abrigo usaria o cabelo assim. É irreal. Todo menino, quando adotado, muda o visual. (APÓS..., 2013).

Ressaltamos que lutar pela construção de práticas antirracistas é bem mais do que colocar um menino negro em cena sendo acolhido por uma família branca. Da mesma maneira que é bem mais do que trazer um menino e negro como principal protagonista de uma história.

Por fim, trazemos para a discussão o livro de Patricia Santana (2008) Minha Mãe é Negra Sim!, que tem o seu início a partir de um conflito vivenciado por Eno, quando a sua professora de Artes o interpela e solicita que pinte o desenho de sua mãe de amarelo, para ficar mais bonito, como pode ser observado no seguinte trecho inicial da narração: "[...] desde o dia em que a professora de Artes disse a ele que pintasse sua mãe de amarelo, que ficava mais bonito. Eno ficou entristecido. Uma tristeza fininha que doía e doía [...]" (SANTANA, 2008, p. 6).

Na sala, não concluiu o desenho, não carregava mais o seu sorriso no rosto na saída da escola, não correu para os braços do seu pai ao chegar em casa na hora do almoço. De acordo com Bischoff (2013, p. 76), a professora estava dizendo para ele e à sua turma cuja pele não tem o tom do lápis apontado por ela: "Vocês não são como deveriam ser!" Eleito pela professora como o lápis que melhor representava "a cor da pele" da mãe de Eno, a professora acabou por reforçar, ao fazer a solicitação, “que há o normal, o ideal, o desejável, e há o anormal, 
o indesejável, o não ideal" (BISCHOFF, 2013, p. 76). Eno, a sua família e sua cor negra não representam o ideal de beleza. A partir dessa triste realidade, Eno passou a vivenciar a sua dor de menino e negro sozinho. Refugiou-se no fundo do quintal: "correu para o seu cantinho lá no terreiro. Cantinho feito com um monte de caixas de banana que ele pegava no sacolão da sua rua. Era um esconderijo de menino" (SANTANA, 2008, p. 12).

Nesse campo de insegurança, instabilidade, desde a infância, Eno vai construindo a sua percepção de mundo. Não queria mais a sua comida preferida, tampouco ir à escola. Vivia amuado e pensativo pelos cantos: "ele era preto, seu pai e sua mãe também. Por que não podia pintar a sua mãe de preto?" (SANTANA, 2008, p. 17). Essas indagações de Eno se resguardam no que afirma Cavalleiro (1998) quando reconhece que a escola e a família desempenham funções de profunda importância no desenvolvimento da criança, afirmando que juntas elas representam a possibilidade de transformação no contexto racial.

De acordo com essa autora, no lar, as características étnico-raciais das crianças são respeitadas, não havendo constantes humilhações baseadas no seu pertencimento. Entretanto, ressalta que o processo de socialização vivenciado nas escolas brasileiras também pode colaborar para que as práticas do racismo e seus derivados sejam utilizados como armas para estabelecer desigualdades nessas relações. Assim, as escolas se constituem em mais uma instituição social em que as características raciais negras são usadas para depreciar, humilhar e excluir. Dessa maneira, não mais protegido no seu lar, Eno começa a entrar em conflito com o mundo branco. Na tentativa de tentar entender o motivo de não poder pintar a sua mãe de preto, ele solicita ao pai que o leve em busca da resposta na biblioteca do bairro. Lá também não encontra alento, pois:

0 carrasco é o homem negro, Satã é negro, fala-se de trevas, quando se é sujo, se é negro - tanto faz que isso se refira à sujeira física ou à sujeira moral. Ficaríamos surpresos se nos déssemos ao trabalho de reunir um grande número de expressões que fazem do negro o pecado. [...] Enquanto não compreendermos esta proposição, estaremos condenados a falar em vão do 'problema negro'. O negro, o obscuro, a sombra, as trevas, à noite, os labirintos da terra, as profundezas abissais, enegrecer a reputação de alguém; e, do outro lado: o olhar claro da inocência, a pomba branca da paz, a luz feérica, paradisíaca. Uma magnífica criança loura, quanta paz nessa expressão, quanta alegria e, principalmente, quanta esperança! Nada de comparável com uma magnífica criança negra, algo absolutamente insólito. (FANON, 2008, p. 160 , grifo do autor).

Para Eno, as definições apresentadas no dicionário o deixaram ainda mais confuso. No entanto, ao se encontrar com o seu avô, homem mais experiente, que imediatamente percebe $o$ seu banzo, o menino revela as suas angústias, busca alento, carinho, colo. De homem para homem, busca solidariedade. Esse desfecho já é uma tendência apontada por Kirchof, Bonin e Silveira (2015), pontuando que tanto pela consulta aos livros, que representam a questão do saber sistematizado, colonialidade do saber (WALSH, 2009), quanto pela consulta aos mais velhos, respeito às memórias coletivas, a tradição oral, a ancestralidade, perspectiva decolonial (WALSH, 2009), são apresentadas soluções para que os personagens negros envolvidos em situações de discriminação racial possam se aceitar. Dessa maneira, o avô de Eno explica para ele sobre o "[...] racismo, das dificuldades que as pessoas negras enfrentaram e enfrentam para serem aceitas nesse mundo" (SANTANA, 2008, p. 22). É na família que Eno encontra o seu refúgio. Entretanto, Hooks (2019) salienta que essa solidariedade não precisa acontecer apenas através da experiência compartilhada e destaca uma questão importante para nós educadores(as):

Portanto, nós podemos ver a necessidade de um tipo de educação para a consciência crítica que pode capacitar quem dispõe do poder e do privilégio baseados nas estruturas de dominação a abrir mão deles sem precisar se ver como vítima. 
Tal pensamento não precisa negar a consciência coletiva de que a cultura de dominação busca fundamentalmente distorcer e perverter a psique de todos os cidadãos, e essa perversão provoca feridas. (HOOKS, 2019, p. 43).

Reeducar a cada um/uma de nós é um grande desafio. Na escola, repensar o currículo mesmo após quase vinte anos da Lei $n^{\circ} 10.639$ (BRASIL, 2003), atual Lei ${ }^{\circ} 11.645$ (BRASIL, 2008), ainda é uma urgência. É preciso tornar a escola um território onde meninos e meninas, desde a Educação Infantil, podem conviver e celebrar a diferença.

A narrativa tem no desfecho seu ápice, no sentido de valorização da identidade negra. Eno não cede. Não volta atrás. Não troca a cor da sua mãe no desenho. Vai para o enfrentamento. Representa o grito de cada menino e negro que busca o reconhecimento da sua identidade de criança e negra, bem como da sua família. "Professora, meu desenho de mãe, não pintei de amarelo, pintei de preto em negro, como é a minha mãe. [...] Pintei da cor de mim mesmo" (SANTANA, 2008, p. 26). Nesse contexto, reconhecemos que a literatura infantil pode atuar estabelecendo novas dinâmicas no contexto das relações étnico-raciais, influenciando na produção das identidades das crianças, dos meninos e negros, posto que também podem veicular e ressignificar as imagens que fogem do padrão hegemônico, ajudando na construção de novas representações de si e do outro.

Resistir para a criança negra é um ato de amor, amor aos seus ideais, amor ao desejo de se ver estrela com todo o brilho e a energia que emanam do fundo do seu ser. Resistir, para a criança negra, é dar vazão ao desejo de se perceber sujeito ativo na construção de um mundo mais humano, é interagir com o cosmo, com a sua beleza negra, o potencial negro e seus valores morais e culturais também negros, é gritar ao mundo com toda a força do seu peito, 'eu me amo e quero ser feliz'. (CERQUEIRA, 2006, p. 113).

\section{Considerações finais}

Ao trazermos para o campo de discussões como as questões de raça e de gênero permeiam algumas narrativas destinadas à Educação Infantil, almejamos evidenciar que a escola tem papel fundamental nesse debate, bem como reconhecemos que os professores não podem improvisar, cabendo-lhes o papel de "desfazer mentalidade racista e discriminadora secular, superando o etnocentrismo europeu, reestruturando relações étnico-raciais e sociais, desalienando processos pedagógicos" (BRASIL, 2004, p. 15). Dessa maneira, precisam atentar para determinadas nuances que permeiam essas narrativas que a priori se apresentam de maneira tão atrativa.

Conforme Candido (2011, p. 175), "a literatura confirma e nega, propõe e denuncia, apoia e combate". Nesse sentido, esse autor também nos alerta que a literatura nem sempre é uma "uma experiência inofensiva, mas uma aventura que pode causar problemas psíquicos e morais, como acontece com a própria vida" (CANDIDO, 2011, p. 113). A respeito dessas considerações, convém destacar que as reflexões tecidas neste artigo visam promover futuros debates sobre a pouca representatividade dos meninos nos livros de literatura que tratam das relações étnico-raciais, bem como solicitar que a construção desses textos seja pensada no sentido de fortalecer a identidade desses meninos e negros e não a partir do pouco cuidado que acaba por fortalecer estereótipos relacionados à masculinidade negra.

Assim, há múltiplas possibilidades para vivenciar, ser e existir como homem e negro, como menino e negro, e os livros de literatura podem apontar esses caminhos, pois, "quer percebamos claramente ou não, o caráter de coisa organizada da obra literária torna-se um fator que nos deixa mais capazes de ordenar a nossa própria mente e sentimentos; e, em consequência, mais capazes de organizar a visão que temos do mundo" (CANDIDO, 2011, p. 177). Dessa forma, desde a Educação Infantil, bebês, crianças bem pequenas e crianças pequenas, meninos e negros, meninas e negras precisam ter a oportunidade de pensar a si, o outro e o mundo a partir do reconhecimento 
e da valorização da sua identidade de criança e negra.

\section{REFERÊNCIAS}

ABRAMOWICZ, Anete; OLIVEIRA, Fabiana. As relações étnico-raciais e a sociologia da infância no Brasil: alguns aportes. In: BENTO, Maria Aparecida Silva (org.). Educação Infantil, igualdade racial e diversidade: aspectos políticos, jurídicos, conceituais. São Paulo: Centro de Estudos das Relações de Trabalho e Desigualdades (CEERT), 2012. p. 47-64.

ABRAMOWICZ, Anete; OLIVEIRA, Fabiana; RODRIGUES, Tatiane Cosentino. A criança negra, uma criança e negra. In: ABRAMOWICZ, Anete; GOMES, Nilma Lino (org.). Educação e raça: perspectivas políticas, pedagógicas e estéticas. Belo Horizonte: Autêntica, 2010. p. 75- 96.

AMARAL, Arleandra Cristina Talin. A infância pequena e a construção da identidade étnico -racial na Educação Infantil. 2013. 225 f. Tese (Doutorado em Educação) - Setor de Educação, Universidade Federal do Paraná (UFPR), Curitiba, 2013.

APÓS nova polêmica, autor de Amor à Vida brinca: "Essa novela tem problema de cabelo". Caras, São Paulo, 20 out. 2013. Disponível em: https://caras. uol.com.br/tv/walcyr-carrasco-autor-amor-vidabrinca-essa-novela-tem-problema-de-cabelopolemica-jayminho.phtml. Acesso em: 01 de mar. de 2021

ARAUJO, Débora Oyayomi Cristina de; SILVA, Paulo Vinicius Baptista. Diversidade étnico-racial e a produção literária infantil: análise de resultados. In: BENTO, Maria Aparecida Silva (org.). Educação infantil, igualdade racial e diversidade: aspectos políticos, jurídicos, conceituais. São Paulo: Centro de Estudos das Relações de Trabalho e Desigualdades (CEERT) , 2012. p. 194-220.

BISCHOFF, Daniela Lemmertz. Minha cor e a cor do outro: Qual a cor dessa mistura? Olhares sobre a racialidade a partir da pesquisa com crianças na Educação Infantil. 2013. 115 f. Dissertação (Mestrado em Educação) - Faculdade de Educação, Universidade Federal do Rio Grande do Sul (UFRGS), Porto Alegre, 2013.

BRASIL. Presidência da República. Casa Civil. Lei no 10.639, de 9 de janeiro de 2003. Altera a Lei no 9.394, de 20 de dezembro de 1996, que estabelece as diretrizes e bases da educação nacional, para incluir no currículo oficial da Rede de Ensino a obrigatoriedade da temática História e Cultura Afro-Brasileira, e dá outras providências. Brasília, DF, 2003. Disponível: https://www.planalto.gov. br/ccivil_03/leis/2003/110.639.htm. Acesso em: 31 jan. 2021.

BRASIL. Ministério da Educação. Conselho Nacional de Educação. Conselho Pleno. Resolução CNE/CP $\mathrm{n}^{\circ}$ 03, de 10 de março de 2004. Diretrizes Curriculares Nacionais para a Educação das Relações Étnico-Raciais e para o Ensino de História e Cultura Afro-Brasileira e Africana. Brasília, DF, 2004. Disponível em: http://portal.mec.gov.br/ dmdocuments/cnecp_003.pdf. Acesso em: 31 jan. 2021.

BRASIL. Presidência da República. Casa Civil. Lei no 11.645, de 10 de março de 2008. Altera a Lei no 9.394 , de 20 de dezembro de 1996, modificada pela Lei no 10.639, de 9 de janeiro de 2003, que estabelece as diretrizes e bases da educação nacional, para incluir no currículo oficial da rede de ensino a obrigatoriedade da temática "História e Cultura Afro-Brasileira e Indígena". Brasília, DF, 2008. Disponível em: http://www.planalto.gov.br/ ccivil_03/_Ato2007-2010/2008/Lei/L11645.htm. Acesso em: 31 jan. 2021.

CANDIDO, Antonio. 0 direito à literatura. In: CANDIDO, Antonio. Vários escritos. Ouro sobre azul. 5. ed. Rio de Janeiro, 2011. p. 171-193.

CAVALLEIRO, Eliane. Do silêncio do lar ao fracasso escolar: racismo, preconceito e discriminação na Educação Infantil. 1998. Dissertação (Mestrado em Educação) - Faculdade de Educação, Universidade de São Paulo (USP), São Paulo, 1998.

CERQUEIRA, Valdimarina Santos. A construção da autoestima da criança negra no cotidiano escolar. 2006. Disponível em: http:// www.acaoeducativa.org. $\mathrm{br} / \mathrm{base} . \mathrm{php}$ ?t=conc_ negro_007\&y=base\&z=08-83k. Acesso em: 05 mar. 2021.

CONNEL, Robert W. Políticas de masculinidade. Revista Educação e Realidade, v. 20, n. 2, p. 185206, 1995. Disponível em: https://seer.ufrgs.br/ educacaoerealidade/article/view/71725/40671. Acesso em: 05 mar. 2021.

CONNELL, Robert W.; MESSERSCHMIDT, James W. Masculinidade hegemônica: repensando o conceito. Revista Estudos Feministas, Florianópolis, v. 21, n. 1, p. 241-282, abr. 2013. Disponível em: http://www.scielo.br/ scielo.php?script=sci_arttext\&pid=S0104- 
026X2013000100014\&lng=en\&nrm=iso. Acesso em: 05 mar. 2021.

CONRADO, Mônica; RIBEIRO, Alan Augusto Moraes. Homem negro, negro homem: masculinidades e feminismo negro em debate. Revista Estudos Feministas, Florianópolis, v. 25, n. 1, p. 7397, abr. 2017. Disponível em: http://www.scielo. br/scielo.php?script=sci_arttext\&pid=S0104026X2017000100073\&lng=pt\&nrm=iso. Acesso em: 05 mar. 2021.

CRENSHAW, Kimberlé. A intersecionalidade da discriminação de raça e gênero. 2002. Disponível em: http://www.acaoeducativa.org. br/fdh/wpcontent/ uploads/2012/09/KimberleCrenshaw.pdf. Acesso em: 22 abr. 2020.

DEBUS, Eliane. A temática da cultura africana e afro-brasileira na literatura para crianças e jovens. São Paulo: Cortez, 2017.

DEBUS, Eliane. Meninos e meninas negras na literatura infantil brasileira: (des)velando preconceitos. Perspectiva, Florianópolis, v. 28, n. 1, p. 191-210, jan./jun 2010. Disponível em: https:// periodicos.ufsc.br/index.php/perspectiva/article/ view/2175-795X.2010v28n1p191/17846. Acesso em: 31 jan. 2021.

FANON, Frantz. Pele negra, máscaras brancas. Salvador: EDUFBA, 2008.

FERNANDES, Florestan. A integração do negro na sociedade de classes: o legado da raça branca. 5 . ed. São Paulo: Globo, 2008. v. 1.

GAIVOTA, Gustavo. Chico Juba. Belo Horizonte: Mazza, 2011.

GOMES, Nilma Lino. Corpo e cabelo como ícones de construção da beleza e da identidade negra nos salões étnicos de Belo Horizonte. 2002. Tese (Doutorado em Antropologia Social) - Universidade de São Paulo (USP). Disponível em: http://www.acaoeducativa.org.br/fdh/wpcontent/uploads/2012/10/Corpo-e-cabelo-comos\%C3\%ADmbolos-da-identidade-negra.pdf. Acesso em: 31 jan. 2021.

GOMES, Nilma Lino. Diversidade cultural, currículo e questão racial: desafios para a prática pedagógica. In: ABRAMOWICZ, Anete; BARBOSA, Lúcia Maria de Assunção Barbosa; SILVÉRIO, Valter Roberto. Educação como prática da diferença. Campinas, SP: Armazém do Ipê, 2006. p. 21-40.

HOOKS, Bell. A vontade de mudar: homens, masculinidade e amor. Tradução Ayodele e Ezequias
Jagge. Rio de Janeiro: Coletivo Nuvem Negra, 2018. Disponível em: https://docero.com.br/doc/ nxs815n. Acesso em: 11 de fev. 2021.

HOOKS, Bell. Olhares negros: raça e representação. Tradução Stephanie Borges. São Paulo: Elefante, 2019.

HOOKS, Bell. We real cool: black man and masculinity. New York: Routledge, 2004.

KIRCHOF, E. R.; BONIN, I. T.; SILVEIRA, R. M. H. A diferença étnico-racial em livros brasileiros para crianças: análise de três tendências contemporâneas. Revista Eletrônica de Educação, v. 9, n. 2, p. 389-412, 2015. Disponível em: http://www.reveduc.ufscar.br/index.php/ reveduc/article/viewFile/1111/416. Acesso em: 31 jan. 2021.

MARTINS, Georgina. Minha família é colorida. São Paulo: SM, 2005.

MUNANGA, Kabengele. Uma abordagem conceitual das noções de raça, racismo, identidade e etnia. In: BRANDÃO, André Augusto P. (org.). Programa de educação sobre o negro na sociedade brasileira. Niterói, RJ, 2004. p. 17-34.

NASCIMENTO, Yago Jose Eloi do; SILVA, Luciana de Mesquita. Masculinidade negra, paternidade e afetividade na literatura infantil: o menino Nito, de Sônia Rosa. Antares - letras e humanidades, v. 12, n. 26, p. 207-227, 2020. Disponível em: http:// www.ucs.br/etc/revistas/index.php/antares / article/view/8702. Acesso em: 05 mar. 2021

REZENDE, Alexander. Cabelo de mola. São Paulo: Paullus, 2012.

RODRIGUES, Tatiane Cosentino; ABRAMOWICZ, Anete. 0 debate contemporâneo sobre a diversidade e a diferença nas políticas e pesquisas em educação. Educação \& Pesquisa, São Paulo, v. 39, n. 1, p. 1530, mar. 2013. Disponível em: http://www.scielo. br/scielo.php?script=sci_arttext\&pid=S151797022013000100002\&lng=en\&nrm=iso. Acesso em: 22 fev. 2021.

ROSA, Sônia. 0 menino Nito: então, homem chora ou não? Rio de Janeiro: Pallas, 2002.

SANTANA, Patricia. Minha mãe é negra sim! Belo Horizonte: Mazza, 2008.

SILVA, Tarcia Regina da. Criança e negra: o direito à afirmação da identidade negra na Educação Infantil. 2015. 223 f. Tese (Doutorado em Educação) - Universidade Federal da Paraíba (UFPB), João Pessoa, 2015. 
SILVA JÚNIOR, Hédio. Anotações conceituais e jurídicas sobre educação infantil, diversidade e igualdade racial. In: BENTO, Maria Aparecida Silva (org.). Educação infantil, igualdade racial e diversidade: aspectos políticos, jurídicos, conceituais. São Paulo: Centro de Estudos das Relações de Trabalho e Desigualdades (CEERT), 2012. p. 65-80.

SOUZA, Neusa Santos. Tornar-se negro: as vicissitudes da identidade do negro brasileiro em ascensão social. Rio de Janeiro: Graal, 1983.

WALSH, Catherine. Interculturalidade crítica e pedagogia decolonial: in-surgir, re-existir e re-viver. In: CANDAU, Vera Maria (org.). Educação Intercultural na América Latina: entre concepções, tensões e propostas. Rio de Janeiro: 7 Letras, 2009. p. 12-42.

WELZER-LANG, Daniel. A construção do masculino: dominação das mulheres e homofobia. Revista Estudos Feministas, Florianópolis, v. 9, n. 2, p. 460-482, 2001. Disponível em: http://www.scielo. $\mathrm{br} /$ scielo.php?script=sci_arttext\&pid=S0104026X2001000200008\&lng=en\&nrm=iso. Accesso em: 20 maio 2021.

ZANETTE, Jaime Eduardo; FELIPE, Jane. Os enigmas da infância: quando a transexualidade tensiona os scripts de gênero. In: ALBUQUERQUE, Simone Santos de; FELIPE, Jane; CORSO, Luciana Vellinho (org.). Para pensar a Educação Infantil em tempos de retrocessos. Porto Alegre: Evangraf, 2017. p. 17-35.

Recebido em: 05/05/2021

Aprovado em: 16/05/2021

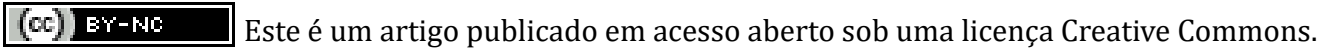

